\title{
Cytokine profile in relapsing-remitting multiple sclerosis patients and the association between progression and activity of the disease
}

\author{
ANA PAULA KALLAUR ${ }^{1}$, SAYONARA RANGEL OLIVEIRA ${ }^{1}$, ANDRÉA NAME COLADO SIMÃO ${ }^{2}$, \\ ELAINE REGINA DELICATO DE ALMEIDA ${ }^{2}$, HELENA KAMINAMI MORIMOTO ${ }^{2}$, \\ JOSIANE LOPES ${ }^{1}$, WILDEA LICE DE CARVALHO JENNINGS PEREIRA ${ }^{3}$, \\ RENATO MARQUES ANDRADE ${ }^{3}$, LARISSA MULITERNO PELEGRINO ${ }^{3}$, SUELI DONIZETE BORELLI ${ }^{4}$, \\ DAMÁCIO RAMON KAIMEN-MACIEL ${ }^{3,5}$ and EDNA MARIA VISSOCI REICHE ${ }^{2}$
}

\begin{abstract}
${ }^{1}$ Health Sciences Postgraduate Program; ${ }^{2}$ Department of Pathology, Clinical Analysis, and Toxicology; ${ }^{3}$ Outpatient Clinic for Multiple Sclerosis, Health Sciences Center, State University of Londrina; ${ }^{4}$ Laboratory of Immunogenetics, Department of Clinical Analysis, State University of Maringá, Paraná; ${ }^{5}$ Department of Clinical Medicine, Health Sciences Center, State University of Londrina, Londrina, Paraná, Brazil
\end{abstract}

Received September 24, 2012; Accepted December 17, 2012

DOI: $10.3892 / \mathrm{mmr} .2013 .1256$

\begin{abstract}
Multiple sclerosis (MS) is a progressive immunemediated disease caused by demyelination of the central nervous system. Cytokines and their receptors have an important role in the evolution of MS lesions, and pro- and anti-inflammatory cytokine levels have been found to correlate with changes in MS disease activity. The aims of the present study were to evaluate the pro-inflammatory [tumor necrosis factor (TNF)- $\alpha$ and interleukin (IL) $-1 \beta,-6$ and -12], T helper (Th) 1 [interferon (IFN)- $\gamma$ ], Th17 (IL-17) and Th2 (IL-4 and -10) cytokine serum levels in relapsing-remitting (RR)-MS patients and to evaluate the association between the cytokine profile and the progression and activity of the disease. Serum cytokine levels were assessed using enzyme linked-immunosorbent assays in 169 RR-MS patients in the remission clinical phase and 132 healthy individuals who were age-, gender-, ethnicity- and body mass index-matched. Disability and activity of the disease were evaluated using the Expanded Disability Status Scale and magnetic resonance imaging with gadolinium, respectively. IFN- $\gamma$ and IL-6, -12 and -4 levels were higher in RR-MS patients compared to controls ( $\mathrm{P}=0.0009,0.0114,0.0297$ and 0.0004, respectively). IL-1 levels were higher in controls compared with RR-MS patients. IL-4 levels were higher in RR-MS patients with mild disability compared to those with moderate and severe disability $(\mathrm{P}=0.0375)$. TNF- $\alpha$ and IL-10 levels were higher in
\end{abstract}

Correspondence to: Dr Edna Maria Vissoci Reiche, Department of Pathology, Clinical Analysis and Toxicology, Health Sciences Center, Londrina State University, 60 Robert Koch Avenue, CEP 86.038-440, Londrina, Paraná, Brazil

E-mail: reiche@sercomtel.com.br

Key words: cytokines, multiple sclerosis, disease activity, disability, disease progression
RR-MS patients with inactive disease compared with those with active disease. IL-17 levels showed a trend towards being higher in RR-MS patients with inactive disease compared to those with active disease $(\mathrm{P}=0.0631)$. Low TNF- $\alpha$ and high IFN- $\gamma$ levels were independently associated with RR-MS $(\mathrm{P}=0.0078$ and 0.0056 , respectively) and also with the activity of the disease $(\mathrm{P}=0.0348$ and 0.0133 , respectively). Results indicated that RR-MS patients, even in the remission clinical phase, exhibit a complex system of inflammatory and anti-inflammatory cytokines that may interact to modulate the progression and activity of the disease.

\section{Introduction}

Multiple sclerosis (MS) is a progressive immune-mediated disease caused by demyelination of the central nervous system (CNS), with perivascular infiltrates of autoreactive T-cells that recognize and react against autoantigens, including myelin basic protein (MBP), proteolipid protein (PLP), myelin oligodendrocytic glycoprotein (MOG) and myelin-associated glycoprotein $(1,2)$. Cytokines and their receptors are important in the evolution of MS lesions, and pro- and anti-inflammatory cytokine levels have been found to correlate with changes in MS disease activity (3).

MS is considered a T helper (Th) 1 lymphocyte-mediated disorder as levels of Th1-related molecules are increased in MS, however, the causes of the disease remain unclear. Th1 lymphocyte cells producing interferon (IFN)- $\gamma$ and tumor necrosis factor (TNF)- $\alpha$ have been found in the perivascular infiltrates of MS patients (4). IFN- $\gamma$ and interleukin (IL)-12 are increased in brain, cerebrospinal fluid (CSF) or peripheral blood of MS patients, particularly during acute exacerbations (5). By contrast, Th2 lymphocyte-related molecules, including IL-10 and -4, which downregulate Th1 cells and exert anti-inflammatory functions, are increased during the remission phases of MS (6). Th17, a subset of T cells that secrete IL-17, has been associated with the pathogenesis of 
several inflammatory diseases, including MS and encephalomyelitis autoimmune experimental (EAE) (7,8). In EAE, Th1 and Th17 cells have been shown to contribute to disease pathogenesis, however, no absolute requirement for IL-17 or IFN- $\gamma$ alone has been reported (9).

Cytokines have been identified as major regulators of the immune system and attempts have been made to correlate cytokine levels with MS disease activity, assessed using magnetic resonance imaging (MRI). There is evidence that acute dysregulation of the balance of cytokines is one of the key factors during acute relapse, leading to acute inflammatory lesions in MS patients. Elevated serum and CSF TNF- $\alpha$ and $-\beta$ levels have been associated with onset of MS relapse (10). Disease progression in MS patients has also been correlated with high CSF TNF- $\alpha$ levels (11).

The clinical disability of MS patients is evaluated using the Expanded Disability Status Scale (EDSS) (12), while the disease activity is evaluated using MRI with gadolinium (Gd)-enhancing lesions, providing the most objective and sensitive tool for assessing the progression and activity of the disease in MS patients. MRI revealed disease activity 5-10 times more frequently than clinical measurements (13). Positive Gd-enhancing lesions are the earliest event in the formation of new MS lesions and are predictive of the course of disability in MS patients (14).

Cytokine changes have been investigated in MS patients from various populations worldwide. The majority of the studies enrolled a limited number of MS patients with various clinical forms of the disease during the remission or relapse phase (15-20). The aims of the present study were to evaluate the serum cytokine profile in RR-MS patients from a Southern Brazilian population and to evaluate the association between the inflammatory and anti-inflammatory cytokine profiles with clinical disability and disease activity of the patients.

\section{Materials and methods}

Study design and subjects. The case-controlled study was approved by the Institutional Research Ethics Committee of the State University of Londrina (Paraná, Brazil) according to the 1964 Declaration of Helsinki and its later amendments. Voluntary written consent was obtained from all individuals prior to the start of the study. The study enrolled 169 consecutive RR-MS patients from the Neurology Outpatients Service of the Outpatient Clinic Hospital, State University of Londrina (Paraná, Brazil), during 2011. RR-MS patients were diagnosed according to the revised McDonald Criteria $(21,22)$. The RR-MS clinical form was determined according to the classification of Lublin and Reingold (23). Demographic, clinical and treatment data of the patients were recorded using a standard questionnaire and medical records. The age at onset of the disease was based on retrospectives data from medical records (21). All the RR-MS patients were in the remission clinical phase, defined as the period of recovery with no relapse episodes within the last three months prior to the time of enrollment in the study. The clinical disability was evaluated using the EDSS (12) at the time of patient enrollment and was categorized as mild (0.0-4.0), moderate (4.5-5.5) and severe (6.0-10.0), according to a previous study (24). The lesion location (brain, spinal cord and optic nerve) and the results of $\mathrm{Gd}$ contrast-enhancing lesions were obtained from the most recent MRI scan performed ( \pm 3 months from enrollment), as described previously $(12,25,26)$. The control group consisted of 132 unrelated healthy blood donors with similar demographic characteristics and who were from the same geographical area as the patients. Blood samples were obtained from the Blood Bank of Londrina (Paraná, Brazil) All the healthy donors presented negative reactivity for serological screening tests for blood donation according to government procedures (27). Control subjects did not present either clinical or laboratory characteristics of autoimmune, infectious or inflammatory diseases. In addition, subjects reported that they were not using any anti-inflammatory drugs or drugs that affect the immune system.

RR-MS patients and control subjects were age-, gender-, ethnicity- and body mass index (BMI)-controlled. Anthropometric measurements were obtained by body weight, measured to the nearest $0.1 \mathrm{~kg}$ using an electronic scale, with individuals wearing light clothing and no shoes. Height was measured to the nearest $0.1 \mathrm{~cm}$ using a stadiometer. BMI was calculated as weight $(\mathrm{kg})$ divided by height $(\mathrm{m})$ squared.

Cytokine measurements. Blood samples for cytokine analysis were collected at the time of patient enrollment. The serum samples of MS patients were immediately separated, divided into aliquots and stored in a $-80^{\circ} \mathrm{C}$ freezer for subsequent analysis, as described previously (28). Serum pro-inflammatory cytokine levels (IL-1 $\beta,-12$ p70 and -6 and TNF- $\alpha$ ) as well as Th1 (IFN- $\gamma$ ), Th2 (IL-4 and -10) and Th17 (IL-17) cytokines were measured with a sandwich enzyme-linked immunosorbent assay using a commercial immunoassay (eBioscience, San Diego, CA, USA), according to the manufacturer's instructions. Results were expressed in $\mathrm{ng} / \mathrm{ml}$. The limit of detection for the cytokines was defined according to the manufacturer's instructions (IL-1 $\beta,-12$ p70 and -17, TNF- $\alpha$ and IFN- $\gamma: 2.0 \mathrm{ng}$ / $\mathrm{ml}$ and IL-6, -4 and -10: $1.0 \mathrm{ng} / \mathrm{ml})$.

Statistical analysis. A database was created using the Excel Program of Microsoft Office and statistical analysis was performed using Graph Pad Prism v5.0 (Graph Pad Software, La Jolla, CA, USA). Categorical variables were analyzed using a Chi-square test (or Fisher's Exact test where appropriate) and were expressed in absolute number and percentage. Continuous variables were analyzed using the Mann-Whitney test and were expressed as the median, interquartile range (IQR; 25-75\%) and range. Continuous variables of two groups or more were compared using the Kruskal-Wallis test with Dunn's post test. $\mathrm{P}<0.05$ was considered to indicate a statistically significant difference. To determine which factors were independently associated with RR-MS, variables that presented $\mathrm{P}<0.20$ in the univariate analyses and values with supposed clinical relevance or previous data in the literature were included in the multivariate logistic regression model. The multivariate analyses were evaluated using GraphPad Instat v3.0 (Graph Pad Software).

\section{Results}

Demographic, anthropometric and clinical characteristics. Demographic and anthropometric characteristics of the 
Table I. Demographic and anthropometric characteristics of RR-MS patients and healthy controls in a population from South Brazil.

\begin{tabular}{lcc}
\hline Characteristics & $\begin{array}{c}\text { RR-MS patients } \\
(\mathrm{n}=169)\end{array}$ & $\begin{array}{c}\text { Healthy controls } \\
(\mathrm{n}=132)\end{array}$ \\
\hline Gender, $\mathrm{n}(\%)$ & & $104(78.8)$ \\
Female & $123(72.8)$ & $28(21.2)$ \\
Male & $46(27.2)$ & $106(80.3)$ \\
Ethnicity, n (\%) & $144(85.2)$ & $26(19.7)$ \\
Caucasian & $25(14.8)$ & $38.5(32.0-46.7)$ \\
Non-Caucasian & & $26.0-62.0$ \\
Age, years & $42.0(30.0-51.5)$ & $0.2604^{\mathrm{a}}$ \\
Median (IQR) & $14.0-85.0$ & $24.8(22.0-27.9)$ \\
Range & & $16.4-40.2$ \\
BMI, kg/m ${ }^{2}$ & $23.5(21.5-27.2)$ & $0.1090^{\mathrm{b}}$ \\
Median (IQR) & $16.9-44.0$ & $0.1120^{\mathrm{b}}$ \\
Range & & \\
\hline
\end{tabular}

${ }^{\mathrm{a} C h i}$-square test $(\mathrm{P}<0.05)$. ${ }^{\mathrm{b}} \mathrm{Mann}$ Whitney test $(\mathrm{P}<0.05)$. RR-MS, relapsing-remitting multiple sclerosis; BMI, body mass index; $\mathrm{IQR}$, interquartile range.

Table II.Clinical characteristics of RR-MS in a population from South Brazil.

\begin{tabular}{|c|c|c|}
\hline Clinical characteristics & $\mathrm{n}$ & RR-MS patients \\
\hline Age at onset, years & 169 & \\
\hline Median (IQR) & & $33.0(24.5-44.0)$ \\
\hline Range & & $10.0-68.0$ \\
\hline Disease duration, years & 169 & \\
\hline Median (IQR) & & $7.0(3.0-10.0)$ \\
\hline Range & & $0.0-52.0$ \\
\hline EDSS, n (\%) & 146 & \\
\hline Mild (0.0-4.0) & & $113(77.2)$ \\
\hline Moderate (4.5-5.5) & & $20(13.8)$ \\
\hline Severe $(6.0-10.0)$ & & $13(9.0)$ \\
\hline Lesion location at MRI, n (\%) & 161 & \\
\hline Brain white matter & & $130(80.8)$ \\
\hline Spinal cord & & $54(33.5)$ \\
\hline Optic nerve & & $18(11.2)$ \\
\hline Disease activity at MRI, n (\%) & 161 & \\
\hline Positive Gd-enhancing lesions & & $35(21.7)$ \\
\hline Negative Gd-enhancing lesions & & $126(78.3)$ \\
\hline RR-MS treatment, n (\%) & 156 & \\
\hline IFN- $\beta 1 \mathrm{a}$ & & $37(23.7)$ \\
\hline IFN- $\beta 1 b$ & & $81(51.9)$ \\
\hline Glatiramer acetate & & $21(13.5)$ \\
\hline Natalizumab & & $03(1.9)$ \\
\hline Treatment naïve & & $05(3.2)$ \\
\hline No adhesion & & $09(5.8)$ \\
\hline Corticosteroids (mg/day) & & $18(10.7)$ \\
\hline
\end{tabular}

RR-MS, relapsing-remitting multiple sclerosis; BMI, body mass index; EDSS, Expanded Disability Status Scale; MRI, magnetic resonance imaging; IQR, interquartile range; IFN, interferon; Gd, gadolinium. 
Table III. Serum cytokine levels obtained from RR-MS patients and healthy controls in a population from South Brazil.

\begin{tabular}{|c|c|c|c|}
\hline Cytokine & $\begin{array}{l}\text { RR-MS } \\
(n=169)\end{array}$ & $\begin{array}{l}\text { Healthy controls } \\
\qquad(\mathrm{n}=132)\end{array}$ & P-value ${ }^{a}$ \\
\hline \multicolumn{4}{|l|}{ IL-1 $\beta$ (pg/ml) } \\
\hline Median (IQR) & $2.0(2.0-2.5)$ & $2.0(2.0-4.5)$ & 0.0992 \\
\hline Range & $2.0-40.7$ & 2.0-63.2 & \\
\hline \multicolumn{4}{|l|}{ IL-6 (pg/ml) } \\
\hline Median (IQR) & $1.9(1.0-3.9)$ & $1.1(1.0-3.4)$ & 0.0114 \\
\hline Range & $1.0-158.0$ & $1.0-49.5$ & \\
\hline \multicolumn{4}{|l|}{ TNF- $\alpha(p g / m l)$} \\
\hline Median (IQR) & $2.0(2.0-4.3)$ & $2.0(2.0-11.2)$ & 0.1840 \\
\hline Range & 2.0-68.4 & 2.0-384.5 & \\
\hline \multicolumn{4}{|l|}{ IL-12 (pg/ml) } \\
\hline Median (IQR) & $2.0(2.0-2.0)$ & $2.0(2.0-2.0)$ & 0.0297 \\
\hline Range & 2.0-93.7 & 2.0-31.1 & \\
\hline \multicolumn{4}{|l|}{ IFN- $\gamma(\mathrm{pg} / \mathrm{ml})$} \\
\hline Median (IQR) & $42.6(23.4-74.9)$ & $24.8(11.7-80.8)$ & 0.0009 \\
\hline Range & $2.0-500.0$ & $2.0-476.7$ & \\
\hline \multicolumn{4}{|l|}{ IL-17 (pg/ml) } \\
\hline Median (IQR) & $2.0(2.0-2.0)$ & $2.0(2.0-2.0)$ & 0.2298 \\
\hline Range & $2.0-53.2$ & 2.0-88.2 & \\
\hline \multicolumn{4}{|l|}{ IL-4 (pg/ml) } \\
\hline Median (IQR) & $1.0(1.0-4.0)$ & $1.0(1.0-1.0)$ & 0.0004 \\
\hline Range & 1.0-26.4 & 1.0-16.1 & \\
\hline \multicolumn{4}{|l|}{ IL-10 (pg/ml) } \\
\hline Median (IQR) & $4.7(3.3-6.5)$ & $4.0(2.9-5.6)$ & 0.1901 \\
\hline Range & $1.0-104.9$ & 1.0-28.2 & \\
\hline
\end{tabular}

${ }^{a}$ Mann Whitney test $(\mathrm{P}<0.05)$. RR-MS, relapsing-remitting multiple sclerosis; IL, interleukin; TNF- $\alpha$, tumor necrosis factor $\alpha$; IFN- $\gamma$, interferon $\gamma$; IQR, interquartile range.

RR-MS patients and healthy individuals are shown in Table I. As expected, the RR-MS patients and controls did not differ in any of the controlled parameters $(\mathrm{P}>0.05)$. The clinical characteristics of RR-MS patients are evident in Table II. The median age at onset of the disease was 33.0 years, with a median disease duration of 7 years. The majority of patients presented mild EDSS and brain white matter lesions without activity. Data of MS therapy revealed the majority of RR-MS patients $(75.6 \%)$ were treated with IFN- $\beta$ and only 18 patients $(10.7 \%)$ were treated with corticosteroids.

Serum cytokine level comparison between RR-MS patients and controls. Serum cytokine levels were compared between RR-MS patients and controls (Table III). With regards to the pro-inflammatory cytokine profile, IL-1 levels were higher among healthy controls compared with RR-MS patients $(\mathrm{P}=0.0992)$. IL-6 and -12 levels were higher in RR-MS patients compared with the controls $(\mathrm{P}=0.0114$ and 0.0297 , respectively). The univariate analysis demonstrated that serum TNF- $\alpha$ levels observed among RR-MS patients did not differ from those of the controls (median, $2.0 \mathrm{pg} / \mathrm{ml}$ and IQR, 2.0-4.3 vs. median, $2.0 \mathrm{pg} / \mathrm{ml}$ and IQR, 2.0-11.2; $\mathrm{P}=0.1840$ ).
In the Th1 cytokine profile, IFN- $\gamma$ levels were higher among RR-MS patients compared with controls $(\mathrm{P}=0.0009)$. However, the Th17 cytokine IL-17 did not differ between RR-MS and controls $(\mathrm{P}=0.2298)$.

Th2 anti-inflammatory cytokine profile results revealed that IL-4 levels were higher in RR-MS patients compared with controls $(\mathrm{P}=0.0004)$. Although IL-10 levels were higher in RR-MS patients compared with controls, this difference was not considered significant $(\mathrm{P}=0.1901)$.

Logistic regression analysis of the results obtained from 169 RR-MS patients and 132 controls included the variables IL-1, -6, -12, - 4 and-10, TNF- $\alpha$ and IFN- $\gamma$ and demonstrated that low TNF- $\alpha$ and high IFN- $\gamma$ levels were independently associated with RR-MS ( $\mathrm{P}=0.0078$ and 0.0056 , respectively).

Serum cytokine level according to EDSS disability scores of $R R$-MS patients. Serum cytokine levels were also evaluated according to the disability of RR-MS patients using categorized EDSS scores in mild, moderate and severe disability (Table IV). Factors, including gender $(\mathrm{P}=0.2357)$, ethnicity $(\mathrm{P}=0.2933)$, BMI $(\mathrm{P}=0.2998)$ and the use of corticosteroids $(\mathrm{P}=0.4333)$, were controlled. However, the age of RR-MS 
Table IV. Serum cytokine levels obtained from RR-MS patients, according to the EDSS.

\begin{tabular}{|c|c|c|c|c|}
\hline Characteristics & Mild EDSS & Moderate EDSS & Severe EDSS & P-value \\
\hline MS patients, $\mathrm{n}$ & 146 & 113 & 13 & \\
\hline Range & $(0.0-4.0)$ & $(4.5-5.5)$ & $(6.0-10.0)$ & \\
\hline \multicolumn{5}{|l|}{ Gender, n (\%) } \\
\hline Female & $83(56.9)$ & $16(11.0)$ & $7(4.8)$ & $0.2357^{\mathrm{a}}$ \\
\hline Male & $30(20.5)$ & $4(2.7)$ & $6(4.1)$ & \\
\hline \multicolumn{5}{|l|}{ Ethnicity, n (\%) } \\
\hline Caucasian & $93(63.7)$ & $19(13.0)$ & $10(6.8)$ & $0.2933^{\mathrm{a}}$ \\
\hline Non-Caucasian & $20(13.7)$ & $01(0.7)$ & $03(2.1)$ & \\
\hline \multicolumn{5}{|l|}{ Age, years } \\
\hline Median (IQR) & $39.0(28.0-48.0)$ & $39.5(34.3-56.0)$ & $52.0(39.5-57.0)$ & $0.0034^{\mathrm{b}}$ \\
\hline Range & 14.0-79.0 & 24.0-85.0 & 29.0-71.0 & \\
\hline \multicolumn{5}{|l|}{ BMI, $\mathrm{kg} / \mathrm{m}^{2}$} \\
\hline Median (IQR) & $23.4(21.7-27.4)$ & $24.8(20.5-27.3)$ & $20.9(19.9-23.9)$ & $0.2998^{b}$ \\
\hline Range & $17.5-44.0$ & 16.9-33.6 & 19.8-24.6 & \\
\hline \multicolumn{5}{|c|}{ Corticosteroids, mg/day ${ }^{\mathrm{c}}$} \\
\hline Median (IQR) & $20.0(20.0-20.0)$ & $25.0(20.0-30.0)$ & $20.0(20.0-20.0)$ & $0.4333^{b}$ \\
\hline Range & $2.0-40.0$ & $20.0-30.0$ & $20.0-20.0$ & \\
\hline \multicolumn{5}{|l|}{$\mathrm{IL}-1 \beta, \mathrm{pg} / \mathrm{ml}$} \\
\hline Median (IQR) & $2.0(2.0-2.0)$ & $2.0(2.0-5.0)$ & $2.0(2.0-2.0)$ & $0.4422^{\mathrm{b}}$ \\
\hline Range & $2.0-40.7$ & $2.0-15.9$ & 2.0-2.0 & \\
\hline \multicolumn{5}{|l|}{ IL-6, pg/ml } \\
\hline Median (IQR) & $1.8(1.0-3.8)$ & $2.1(1.0-3.9)$ & $3.9(1.3-4.9)$ & $0.7408^{b}$ \\
\hline Range & 1.0-122.3 & 1.0-158.0 & 1.0-5.6 & \\
\hline \multicolumn{5}{|l|}{ TNF- $\alpha, p g / m l$} \\
\hline Median (IQR) & $2.0(2.0-5.0)$ & $2.0(2.0-3.3)$ & $2.7(2.0-28.8)$ & $0.0572^{b}$ \\
\hline Range & $2.0-50.1$ & $2.0-4.7$ & $2.0-30.0$ & \\
\hline \multicolumn{5}{|l|}{ IL-12, pg/ml } \\
\hline Median (IQR) & $2.0(2.0-2.0)$ & $2.0(2.0-2.0)$ & $2.0(2.0-4.5)$ & $0.5083^{\mathrm{b}}$ \\
\hline Range & $2.0-93.7$ & $2.0-7.5$ & $2.0-11.8$ & \\
\hline \multicolumn{5}{|l|}{ INF- $\gamma, p g / m l$} \\
\hline Median (IQR) & $41.2(19.6-77.7)$ & $55.5(27.1-36.3)$ & $52.6(36.3-72.0)$ & $0.6032^{b}$ \\
\hline Range & $5.0-500.0$ & 9.8-500.0 & $27.0-500.0$ & \\
\hline \multicolumn{5}{|l|}{ IL-17, pg/ml } \\
\hline Median (IQR) & $2.0(2.0-2.0)$ & $2.0(2.0-2.0)$ & $2.0(2.0-5.5)$ & $0.2359^{\mathrm{b}}$ \\
\hline Range & $2.0-53.2$ & 2.0-4.2 & $2.0-13.7$ & \\
\hline \multicolumn{5}{|l|}{ IL-4,pg/ml } \\
\hline Median (IQR) & $1.0(1.0-9.6)$ & $1.0(1.0-1.4)$ & $1.0(1.0-1.0)$ & $0.0375^{\mathrm{b}}$ \\
\hline Range & $1.0-26.4$ & $1.0-17.2$ & 1.0-1.0 & \\
\hline \multicolumn{5}{|l|}{ IL-10, pg/ml } \\
\hline Median (IQR) & $4.6(3.2-6.6)$ & $4.4(3.4-6.8)$ & $5.0(3.0-5.2)$ & $0.8680^{\mathrm{b}}$ \\
\hline Range & $1.0-21.9$ & $2.2-16.5$ & 2.9-5.4 & \\
\hline
\end{tabular}

${ }^{\mathrm{a}}$ Chi-square test $(\mathrm{P}<0.05) .{ }^{\mathrm{b}}$ Kruskal-Wallis test with Dunn's Post test $(\mathrm{P}<0.05)$. ${ }^{\mathrm{c}}$ Eighteen RR-MS patients were treated with corticosteroids at the time of enrollment in the study. RR-MS, relapsing-remitting multiple sclerosis; EDSS, Expanded Disability Status Scale; IL, interleukin; TNF- $\alpha$, tumor necrosis factor $\alpha$; IFN- $\gamma$, interferon $\gamma$; IQR, interquartile range.

patients that exhibited severe disability was higher than that of RR-MS patients with mild and moderate disability $(\mathrm{P}=0.0034)$.
Serum IL-1 levels did not differ according to the disability exhibited by the RR-MS patients ( $\mathrm{P}=0.4422)$. Although IL-6, TNF- $\alpha$ and IFN- $\gamma$ levels were higher among the RR-MS 
Table V. Serum cytokine levels obtained from RR-MS patients according to Gd-enhancing lesions assessed by MRI.

\begin{tabular}{|c|c|c|c|}
\hline \multirow[b]{2}{*}{ Characteristics } & \multicolumn{2}{|c|}{ MRI } & \multirow[b]{2}{*}{$\mathrm{P}$-value } \\
\hline & Positive Gd & Negative Gd & \\
\hline RR-MS patients, $\mathrm{n}$ & 35 & 126 & \\
\hline \multicolumn{4}{|l|}{ Gender, n (\%) } \\
\hline Female & $24(14.9)$ & $93(57.8)$ & \multirow[t]{2}{*}{$0.5383^{\mathrm{a}}$} \\
\hline Male & 11(6.8) & $33(20.5)$ & \\
\hline \multicolumn{4}{|l|}{ Ethnicity, n (\%) } \\
\hline Caucasian & $29(18.0)$ & 107 (66.5) & \multirow[t]{2}{*}{$0.7656^{\mathrm{a}}$} \\
\hline Non-Caucasian & $06(3.7)$ & $107(66.5)$ & \\
\hline \multicolumn{4}{|l|}{ Age, years } \\
\hline Median (IQR) & $32.0(27.0-44.0)$ & $44.0(32.0-52.3)$ & \multirow[t]{2}{*}{$0.0032^{b}$} \\
\hline Range & 14.0-79.0 & $15.0-85.0$ & \\
\hline \multicolumn{4}{|l|}{$\mathrm{BMI}, \mathrm{kg} / \mathrm{m}^{2}$} \\
\hline Median (IQR) & $23.4(22.1-27.7)$ & $23.5(21.1-27.1)$ & \multirow[t]{2}{*}{$0.6464^{b}$} \\
\hline Range & 19.3-35.5 & 16.9-44.0 & \\
\hline \multicolumn{4}{|c|}{ Corticosteroids, mg/day ${ }^{\mathrm{c}}$} \\
\hline Median (IQR) & $20.0(20.0-20.0)$ & $20.0(20.0-22.5)$ & \multirow[t]{2}{*}{$0.9029^{b}$} \\
\hline Range & $20.0-40.0$ & $5.0-30.0$ & \\
\hline \multicolumn{4}{|l|}{$\mathrm{IL}-1 \beta, \mathrm{pg} / \mathrm{ml}$} \\
\hline Median (IQR) & $2.0(2.0-2.0)$ & $2.0(2.0-2.9)$ & \multirow[t]{2}{*}{$0.4752^{b}$} \\
\hline Range & $2.0-18.0$ & $2.0-40.7$ & \\
\hline \multicolumn{4}{|l|}{ IL-6, pg/ml } \\
\hline Median (IQR) & $1.3(1.0-3.2)$ & $2.4(1.0-4.0)$ & \multirow[t]{2}{*}{$0.1129^{b}$} \\
\hline Range & $1.0-158.0$ & $1.0-122.3$ & \\
\hline \multicolumn{4}{|l|}{ TNF- $\alpha, p g / m l$} \\
\hline Median (IQR) & $2.0(2.0-2.1)$ & $2.0(2.0-5.6)$ & \multirow[t]{2}{*}{$0.0457^{b}$} \\
\hline Range & $2.0-17.5$ & $2.0-68.4$ & \\
\hline \multicolumn{4}{|l|}{$\mathrm{IL}-12, \mathrm{pg} / \mathrm{ml}$} \\
\hline Median (IQR) & $2.0(2.0-2.0)$ & $2.0(2.0-2.0)$ & \multirow[t]{2}{*}{$0.9089^{b}$} \\
\hline Range & $2.0-48.3$ & $2.0-93.7$ & \\
\hline \multicolumn{4}{|l|}{$\mathrm{IFN}-\gamma, \mathrm{pg} / \mathrm{ml}$} \\
\hline Median (IQR) & $52.8(25.0-131.4)$ & $39.5(23.0-70.7)$ & \multirow[t]{2}{*}{$0.1643^{b}$} \\
\hline Range & 6.4-500.0 & 2.0-500.0 & \\
\hline \multicolumn{4}{|l|}{ IL-17, pg/ml } \\
\hline Median (IQR) & $2.0(2.0-2.0)$ & $2.0(2.0-2.6)$ & \multirow[t]{2}{*}{$0.0631^{\mathrm{b}}$} \\
\hline Range & $2.0-15.6$ & $2.0-53.2$ & \\
\hline \multicolumn{4}{|l|}{ IL-4, pg/ml } \\
\hline Median (IQR) & $1.0(1.0-14.9)$ & $1.0(1.0-4.1)$ & $0.8980^{\mathrm{b}}$ \\
\hline Range & $1.0-22.3$ & $1.0-26.4$ & \\
\hline IL-10, pg/ml & & & \\
\hline Median (IQR) & $3.4(2.3-5.8)$ & $4.9(3.4-6.5)$ & $0.0533^{b}$ \\
\hline Range & $1.0-15.9$ & $1.0-104.9$ & \\
\hline
\end{tabular}

${ }^{a}$ Chi-square test $(\mathrm{P}<0.05) .{ }^{b}$ Mann Whitney test $(\mathrm{P}<0.05)$. ${ }^{\mathrm{c}}$ Eighteen RR-MS patients were treated with corticosteroids at the time of enrollment in the study. RR-MS, relapsing-remitting multiple sclerosis; BMI, body mass index; IL, interleukin; TNF- $\alpha$, tumor necrosis factor $\alpha$; IFN- $\gamma$, interferon $\gamma$; IQR, interquartile range; Gd, gadolinium.

patients with severe disability compared with those observed among the RR-MS patients with moderate and mild disability, the difference was not significant $(P=0.7408,0.6896$ and
0.6032 , respectively). No significant difference was found in IL-12 and -17 levels obtained among the RR-MS patients with mild, moderate and severe disability $(\mathrm{P}=0.5083$ and 
0.2359, respectively). Higher IL-4 levels were observed among RR-MS patients with mild disability compared with moderate and severe disability $(\mathrm{P}=0.0375)$. However, no difference was observed in IL-10 levels with respect to patient disability $(\mathrm{P}=0.8680)$. Following logistic regression analysis, variables presented no independent association with disease disability $(\mathrm{P}>0.05)$.

Serum cytokine level according to disease activity. Serum cytokine levels obtained from RR-MS patients were also evaluated according to the disease activity assessed by Gd-enhancing lesions observed during MRI (Table V). Factors, including gender $(\mathrm{P}=0.5383)$, ethnicity $(\mathrm{P}=0.7656)$, BMI $(\mathrm{P}=0.6464)$ and the use of corticosteroids $(\mathrm{P}=0.9029)$ were controlled. However, the age of RR-MS patients with positive Gd-enhancing lesions was lower compared with RR-MS patients with negative Gd-enhancing lesions $(\mathrm{P}=0.0032)$.

No difference was detected in IL-1, -6, -12 and -4 levels between RR-MS patients with positive and negative Gd-enhancing lesions ( $\mathrm{P}=0.4752,0.1129,0.9089$ and 0.8980 , respectively). Although $\mathrm{IFN}-\gamma$ levels were higher among RR-MS patients presenting positive Gd-enhancing lesions compared with negative ones, no difference was found by univariate analysis $(\mathrm{P}=0.1643)$. TNF- $\alpha$ levels were higher in patients with negative Gd-enhancing lesions than positive $(\mathrm{P}=0.0572)$. Serum IL 17 levels showed a growing trend towards being higher in RR MS patients with inactive disease compared to those with active disease $(\mathrm{P}=0.0631)$. While serum IL-10 levels were higher among RR-MS patients with negative $\mathrm{Gd}$-enhancing lesions than those with positive $(\mathrm{P}=0.0533)$. IL-4 levels did not differ between these patients $(\mathrm{P}=0.8980)$.

Logistic regression analysis between the results obtained from RR-MS patients and the disease activity, including the variables age, TNF- $\alpha$, IFN- $\gamma$ and IL- $6,-17$ and -10 , demonstrated that low TNF- $\alpha$ and high IFN- $\gamma$ levels were independently associated with disease activity $(\mathrm{P}=0.0348$ and 0.0133 , respectively).

\section{Discussion}

The present study evaluated the serum cytokine profile exhibited by RR-MS patients in a remission clinical phase from a population from South Brazil. Theoretically, CSF may reflect the relevant inflammatory process to a higher degree compared with other samples, due to its proximity to inflammatory lesions in the CNS. However, due to the flow pattern of CSF, it is unlikely that CSF in the lumbar cistern accurately reflects the production of inflammatory markers in the supratentorial region, where the majority of MS-related inflammation occurs (29). In addition, CSF collection is an invasive procedure, the intraparenchymal extracellular space may not necessarily communicate with the free CSF space (30) and it remains unclear whether CSF markers possess definite advantages over markers collected from blood and/or urine (29). Therefore, in the current study the cytokine profile was measured in serum samples.

To obtain more homogeneity of the cohort, only patients with the RR-MS clinical form were included in this study. The main result obtained in this study was elevated serum IFN- $\gamma$ and IL-6, -12 and -4 levels in RR-MS patients compared with controls. MS patients with mild EDSS presented elevated IL-4 levels. RR-MS patients with inactive disease exhibited elevated levels of TNF- $\alpha$ and IL-10 and -17. Logistic regression analysis revealed that low TNF- $\alpha$ and high IFN- $\gamma$ levels were associated with MS and disease activity.

The demographic and clinical characteristics exhibited by the RR-MS patients are consistent with those of previous studies $(18,24,31,34)$. The majority of RR-MS patients exhibited mild clinical disability, predominance of lesions in brain white matter and low disease activity. These results were expected considering all the RR-MS patients were in clinical remission and the majority of them were treated with IFN- $\beta$ (1a or b) which has been demonstrated to decrease clinical disability and disease activity (18,35-37).

RR-MS patients and controls were age-, gender-, ethnicityand BMI-matched for cytokine analysis. These parameters were controlled to minimize their effect of them on serum cytokine levels $(38,39)$. IL-1 levels were higher among controls compared with RR-MS patients and may be explained by the hypothesis that IFN- $\beta$ therapy decreases IL- $1 \beta$ expression in the dendritic cells and monocytes of RR-MS patients (40). This pro-inflammatory cytokine is considered an important mediator for neuronal and axonal damage of the CNS in MS patients. One of the actions of IL-1 $\beta$ in the brain is the induction of astrogliosis by astrocyte activation and IL- 6 production, an effect that is markedly augmented in the presence of TNF- $\alpha$, IFN- $\gamma$, IL- 6 and the IL-6 receptor (41). However, IL-1 has also been revealed to induce proliferation of the nerve growth factor in vitro and may exhibit protective effects in MS patients (42).

The increased IL-6 levels identified among RR-MS patients compared with controls are consistent with previous studies. One study demonstrated that the number of IL-6 mRNA expressing mononuclear cells was enriched in CSF of MS patients (43). Increased IL-6 production was also observed in peripheral blood monocytes and macrophages stimulated with LPS from MS patients (44). IL-6 deficient mice were found to be resistant to induction of EAE (17) and also revealed a reduction of anti-MOG antibody titers, vascular cell adhesion molecule-1 (VCAM-1) and intercellular adhesion molecule-1 (ICAM-1) molecule expression, which may affect the entry of Th1 cells into the CNS (45). By contrast, IL-6 also presented beneficial effects, including anti-inflammatory properties. IL-6 inhibits IL- $1 \beta$ and TNF- $\alpha$ secretion in vitro (46) and induces circulating IL-1 receptor antagonist in vivo (47). Results of the current study are consistent with those of previous studies considering that elevated IL-6 levels were found in RR-MS patients, IL-1 levels were higher in controls and no difference was observed in TNF- $\alpha$ levels.

Navikas et al (48) demonstrated that MS patients present with high numbers of MBP-reactive cells in their blood which, following culture with MBP and myelin PLP, respond to production and secretion of additional cytokines, including IFN- $\gamma$, IL- 4 , transforming growth factor $\beta$ (TGF- $\beta$ ), IL-10 and TNF- $\alpha$. The authors of that study demonstrated that MS patients presented elevated MBP- and PLP-reactive IL-6 mRNA expressing cells in the peripheral blood. Cytokines are known to modulate production of other cytokines (49). Therefore, IL-6 functions with additional cytokines within the cytokine network. 
TNF- $\alpha$ levels were lower in RR-MS patients than the controls, as demonstrated by the multivariate analysis. This result is consistent with previous studies reporting lower TNF- $\alpha$ levels in MS patients compared with controls $(11,19)$. Decreased production of TNF- $\alpha$ by stimulated PBMCs from MS patients compared with controls was also demonstrated (3).

In the present study, increased IFN- $\gamma$ levels obtained among MS patients compared with controls were also consistent with previous studies. Lymphocytes producing IFN- $\gamma$ were identified in the perivascular infiltrates of MS patients (4). A previous study evaluated mRNA serum transcript in patients receiving various doses of IFN- $\beta 1 \mathrm{~b}$ and confirmed that IFN- $\beta$ decreases the expression of Th1 inflammatory molecules, including IFN- $\gamma$ and TNF- $\alpha$. In addition, IFN- $\beta$ increases the Th2-related molecule IL-10 (3).

Although IL-17 expression has been demonstrated to generate a highly pro-inflammatory environment and to induce severe pathological conditions (50), in the present study no difference was observed in IL-17 levels between MS patients and controls. A previous study (51) revealed that the proportion of Th17 cells in patients with relapses were significantly higher compared with patients during remission, in clinically isolated syndrome (CIS) and RR-MS clinical forms of MS. Another study (52) also revealed that IFN- $\beta$ inhibits IL-23 which is involved in the differentiation of Th0 (naïve) to Th17 cells and, consequently, IL-17 production. In addition, IFN- $\beta$ therapy inhibits the IL-27 cytokine which, in turn, inhibits Th17 cells directly and through the inhibition of IL-23, promotes development of these pathogenic T cells (8). IL-23 and -12 exert antagonistic effects. While IL-23 supports IL-17 production, IL-12 inhibits this production (53). IL-17, in turn, stimulates astrocyte IL-6 production and macrophage production of IL-6, TNF- $\alpha$ and IL-1 $\beta$, cytokines that are involved in MS pathology (54).

The RR-MS patients enrolled in this study presented high levels of IL-12 which, in turn, antagonized IL-17 production and by this effect, reduced IL- $1 \beta$ - and TNF- $\alpha$-induced production by IL-17. In addition to the consumption of TNF- $\alpha$ in CNS lesions, the reduced production may explain, in part, why TNF- $\alpha$ levels did not differ among the patients and controls (54).

The higher IL-12 levels exhibited by RR-MS patients compared with controls enrolled in the present study are also consistent with previous observations that IL-12 levels were upregulated in MS patients (55). Overexpression of IL-12 in the CNS resulted in increased inflammation and cellular infiltrates (56). Although several studies have suggested a key pro-inflammatory role for IL-12 in the development of autoimmune responses, controversial results have been reported with respect to IL-12 levels obtained from MS patients and MS patients treated with IFN- $\beta$. A previous study (40) demonstrated that treatment with IFN- $\beta 1$ a significantly induces IL-12p35 gene expression in dendritic cells from RR-MS patients. By contrast, it was demonstrated that treatment with IFN- $\beta$ inhibits IL-12 and decreases C-X-C motif chemokine 10, IL-18, IFN- $\gamma$ and TNF- $\alpha$ (57). However, this therapy increases IL-10 and TGF- $\beta$ levels (58).

In the Brazilian cohort enrolled in the present study, higher levels of IL-4 were found in MS patients compared with controls, a result consistent with previous studies $(59,60)$.
IL-4 mRNA was previously revealed to be undetectable until disease remission in SJL mice immunized with PLP (61). IL-4 is a key cytokine produced by Th2 cells and inhibits Th1 cells by decreasing IL-1 and TNF- $\alpha$ cytokines. Administration of IL-4 in EAE exerts an ameliorating and protective effect. Studies demonstrated that IL-4 upregulation may reduce the severity of EAE, while its absence does not alter the course of the disease, possibly since in the absence of IL-4, an additional Th2 cytokine may substitute its functions and contribute to the tolerance of EAE (62).

Although IL-10 levels were higher in MS patients compared with controls, no statistically significant difference was found. It was previously suggested that IL-10 is important for recovery of EAE (63). In contrast to other Th2 cytokines (IL-4), the absence of IL-10 results in a more severe EAE, indicating that its function cannot be replaced by an additional Th2 cytokine.

The cytokine profile was also evaluated according to the EDSS of the RR-MS patients. Patients with mild disability were younger than those with moderate and severe disability, a result that was expected since at the beginning of the disease, low EDSS scores are detected among RR-MS patients and disability increases during disease progression (64). However, logistic regression analysis revealed no effect of age in the cytokine profile according to the EDSS. Although higher serum IL-6, TNF- $\alpha$, IFN- $\gamma$ and IL-12 levels were found in RR-MS patients with moderate and severe disability than those with mild disability, no significant differences were identified. As observed, the results of TNF- $\alpha$ levels are contradictory in various clinical disabilities. While low levels of TNF- $\alpha$ have been reported in specific MS patients $(11,19)$, another study reported that TNF- $\alpha$ is the principal mediator of inflammatory response and is increased among MS patients, indicating that this cytokine is an important molecule in the pathogenesis and progression of MS (65).

In addition, serum IL-17 and -10 did not differ between EDSS categories. Several studies have reported that differential production of IL-10 may be a factor in the severity of MS (31,63). With regards to serum IL-4 levels, results demonstrate a significant increase of this cytokine among RR-MS patients suffering from mild disability compared with those with moderate or severe disability. This result confirms the important role of IL-4 as an anti-inflammatory modulator of MS lesion formation $(6,19)$.

It was not possible to control age of RR-MS patients with regards to disease activity. However, logistic regression analysis revealed that age did not affect cytokine levels. There is evidence that an acute deregulation in the balance of cytokines is one of the key factors during an acute relapse leading to acute inflammatory lesions. RR-MS patients with active disease presented with lower TNF- $\alpha$ and higher IFN- $\gamma$ levels compared with RR-MS patients without active disease, as demonstrated by multivariate analysis. IFN- $\gamma$ and IL-12 levels were increased in brain, CSF or peripheral blood from MS patients, particularly during acute exacerbation phases (5). Previously, Begolka and Miller (61) observed that IFN- $\gamma$ expression increases during the peak of the disease and decreases during the remission phase. Clinical attacks correlate with increased IFN- $\gamma$ production (66) and patients experiencing relapses have significantly increased IFN- $\gamma$ production by PBMCs following stimulation with PHA 
compared with patients in remission. However, this production was reduced following treatment with IFN- $\beta$ (67). IFN- $\gamma$ is produced within MS lesions by infiltrating lymphocytes and induces apoptosis in human oligodendrocytes (68).

Cytokines only function when bound to membrane receptors and the TNF- $\alpha$ receptor is present in almost all cells $(6,61,69)$. In MS patients, TNF- $\alpha$ is produced and consumed at sites of inflammation, including lesions in brain white matter, spinal cord and optic nerve $(70,71)$. TNF- $\alpha$ and $-\beta$ cytokines were detected in astrocytes from demyelinating plaques (71), contributing to white matter destruction at the onset of MS (16). Results obtained in the present study are consistent with these previous findings. However, serum TNF- $\alpha$ levels measured in RR-MS patient samples of the present study may be the remaining expressed cytokines, neither acting at lesions on the CNS, nor binding to transmembrane or soluble receptors. Additional studies also demonstrated lower serum TNF- $\alpha$ levels in MS patients in remission compared with those in the relapse clinical phase $(19,20)$.

Although IL-6 levels were higher in RR-MS patients with inactive disease, this difference was not identified to be statistically significant. This result is in agreement with a previous study (72) which demonstrated that macrophages within the MS lesion expressed IL-6 and the highest number of IL-6 expressing cells were found in inactive demyelination lesions. We hypothesize that IL- 6 also has anti-inflammatory properties (46) that may affect disease activity.

A previous study has demonstrated that serum IL-12 levels correlate with active lesions (73), however, no significant difference was observed in serum IL-12 levels obtained from RR-MS patients with positive and negative Gd-enhancing lesions enrolled in the present study.

Increased levels of IL-17 were found in RR-MS patients with inactive disease. Th17 cell differentiation is orchestrated by multiple cytokines, including TGF- $\beta$ and IL- $6,-1-\beta,-21$ and -23 (stimulating) and IFN- $\gamma$ and IL-4, $-12,-10$ and -27 (inhibiting). The Th17 cell is a recently identified cell lineage that has been hypothesized to be critical for the development of the autoimmune response, in addition to Th1 cells (74). Studies from MS patients indicated that IL-17 mRNA is elevated in active MS brain lesions. IL-17 was also detected at lesions (75).

Serum IL-4 levels did not differ between RR-MS patients with active and inactive disease and this result was not consistent with previous studies that demonstrated high IL-4 levels in acute and chronic lesions (62). However, in the present study, serum IL-10 levels were high among RR-MS patients with inactive lesions. This result is consistent with previous observations of increased production of IL-10 and TGF- $\beta$ by isolated lymphocyte clones of MS patients in remission (76). Decreased IL-10 levels were found prior to onset of exacerbation in RR-MS patients (15). IL-10 levels were also significantly decreased in MS patients with the secondary progressive form of MS compared with patients at four weeks prior to detection of MS by MRI and six weeks prior to clinical relapse (73).

Previously, Cannella and Raine (62) reported that the expression of adhesion molecules, including VCAM-1, ICAM-1 and their receptors on leukocytes, very late activation antigen-4 (VLA-4) and lymphocyte function-associated antigen-1
(LFA-1), respectively, together with a selection of pro-inflammatory and immunomodulatory cytokines including, IL-1, $-2,-4$ and -10 , TNF- $\alpha$, TGF- $\beta$ and IFN- $\gamma$, are important for lymphocytic infiltration and interactions during tissue inflammation. In general, these molecules are not expressed by CNS cells. The authors identified high levels of these molecules in MS patients, particularly in those with chronic active lesions and also found a significantly increased expression of TNF- $\alpha$ and IL-4 in MS compared with non-inflammatory neurological diseases (62).

The present study demonstrates that RR-MS patients exhibit a complex system of cytokines which interact to modulate disease activity and the disabilities associated with it. Even in the remission phase of the disease and under immunomodulatory therapy, RR-MS patients present with an imbalance between pro-inflammatory, Th1, -2 and -17 cytokines. TNF- $\alpha$ was observed to be consumed in CNS lesions and activation of the cellular immune response was mediated by high levels of IFN- $\gamma$. These results are likely to contribute to an improved understanding of the role of the cytokine profile in RR-MS and may aid the development of new neuroprotective and neurorestorative therapeutic strategies.

\section{Acknowledgements}

The present study was supported by grants from the Coordination for the Improvement of Higher Level of Education Personnel of Brazilian Ministry of Education, Institutional Program for Scientific Initiation Scholarship of the National Council for Scientific and Technological Development, State University of Londrina and Bayer HealthCare. The authors thank the State University of Londrina and HUTec Foundation for technical and administrative support.

\section{References}

1. Sospedra M and Martin M: Immunology of multiple sclerosis. Annals Review Immunology 23: 683-747, 2005.

2. Cucci A, Barbero P, Clerico M, Ferrero B, Versino E, Contessa G, Demercanti S, Viglietta E, Di Liberto A, Vai AG and Durelli L: Pro-inflammatory cytokine and chemokine mRNA blood level in multiple sclerosis is related to treatment response and interferon-beta dose. J Neuroimmunol 226: 150-157, 2010.

3. Graber JJ, Ford D, Zhan M, Francis G, Panitch H and Dhib-Jalbut S: Cytokine changes during interferon-beta therapy in multiple sclerosis: correlation with interferon dose and MRI response. J Neuroimmunol 185: 168-174, 2007.

4. Dihb-Jalbut S, Arnold DL, Cleveland DW, Fisher M, Friedlander RM, Mouradian MM, Przedborski S, Trapp BD, Wyss-Coray T and Yong VW: Neurodegeneration and neuroprotection in multiple sclerosis and other neurodegenerative diseases. J Neuroimmunol 176: 198-215, 2006.

5. Huang WX, Huang P and Hillert J: Increased expression of caspase-1 and interleukin-18 in peripheral blood mononuclear cells in patients with multiple sclerosis. Mult Scler 10: 482-487, 2004.

6. Imitola J, Chitnis T and Khoury SJ: Cytokines in multiple sclerosis: from bench to bedside. Pharmacol Ther 106: 163-177, 2005.

7. Sutton CE, Lalor SJ, Sweeney CM, Brereton CF, Lavelle EC and Mills KH: Interleukin-1 and IL-23 induce innate IL-17 production from gammadelta $\mathrm{T}$ cells, amplifying Th17 responses and autoimmunity. Immunity 31: 331-341, 2009.

8. Sweeney CM, Lonergan R, Basdeo SA, Kinsella K, Dungan LS, Higgins SC, Kelly PJ, Costelloe L, Tubridy N, Mills KH and Fletcher JM: IL-27 mediates the response to IFN- $\beta$ therapy in multiple sclerosis patients by inhibiting Th17 cells. Brain Behav Immun 25: 1170-1181, 2011. 
9. Domingues HS, Mues M, Lassmann H, Wekerle $\mathrm{H}$ and Krishnamoorthy G: Functional and pathogenic differences of Th1 and Th17 cells in experimental autoimmune encephalomyelitis. PLoS One 5: e15531, 2010.

10. Rudick RA and Rosahoff RM: Cytokine secretion by multiple sclerosis monocytes. Arch Neurol 49: 265-270, 1992.

11. Duddy ME, Armstrong MA, Crockard AD and Hawkins SA: Changes in plasma cytokines induced by interferon-beta 1a treatment in patients with multiple sclerosis. J Neuroimmunol 101: 98-109, 1999.

12. Kurtzke JF: Rating neurologic impairment in multiple sclerosis: an expanded disability status scale (EDSS). Neurology 33 1444-1452, 1983

13. Kermode AG, Thompson AJ, Tofts P, Macmanus DG, Kendall BE, Kingsley DP, Moseley IF, Rudge P and McDonald WI: Breakdown of the blood-brain barrier precedes symptoms and other MRI signs of new lesions in multiple sclerosis. Brain 113 $1477-1489,1990$

14. Barkhof F: MRI in multiple sclerosis: correlation with expanded disability status scale (EDSS). Mult Scler 5: 283-286, 1999.

15. Rieckmann P, Albrecht M, Kitze B, Weber T, Tumani H, Broocks A, Lüer W and Poser S: Cytokine mRNA levels in mononuclear blood cells from patients with multiple sclerosis. Neurology 44: 1523-1526, 1994

16. Olsson T: Cytokine-producing cells in experimental autoimmune encephalomyelitis and multiple sclerosis. Neurology 45 (Suppl 6): S11-S15, 1995

17. Okuda Y, Sakoda S, Fujimura H, Saeki Y, Kishimoto T and Yanagihara T: IL-6 plays a crucial role in the induction phase of myelin olygodendrocyte glucoprotein 35-55 induced experimental autoimmune encephalocyelitis. J Neuroimmunol 10: 188-196, 1999.

18. Kraus J, Kuehne BS, Tofighi J, Frielinghaus P, Stolz E, Blaes F, Laske C, Engelhardt B, Traupe H, Kaps M and Oschmann P: Serum cytokine levels do not correlate with disease activity and severity assessed by brain MRI in multiple sclerosis. Acta Neurol Scand 105: 300-308, 2002.

19. Trenova AG, Manova MG, Kostadinova II, Hrsitova DR, Vasileva TV and Zahariev ZI: Clinical and laboratory study of pro-inflammatory and anti-inflammatory cytokines in women with multiple sclerosis. Folia Med (Plovdiv) 53: 29-35, 2011.

20. Obradović D, Kataranovski M, Dincić E, Obradović S and Colić M: Tumor necrosis factor-alpha and interleukin-4 in cerbrospinal fluid and plasma in different clinical forms of multiple sclerosis. Vojnosanit Pregl 69: 151-156, 2012.

21. Polman CH, Reingold SC, Edan G, Filippi M, Hartung HP, Kappos L, Lublin FD, Metz LM, Mcfarland HF, O'Connor PW, Sandberg-Wollheim M, Thompson AJ, Weinshenker BG and Wolinsky JS: Diagnostic criteria for multiple sclerosis: 2005 revisions to the 'McDonald Criteria'. Ann Neurol 58: 840-846, 2005.

22. Polman $\mathrm{CH}$, Reingold SC, Banwell B, Clanet M, Cohen JA, Filippi M, Fujihara K, Havrdova E, Hutchinson M, Kappos L, Lublin FD, Montalban X, O'Connor PK, O'Connor PW, SandbergWollheim M, Thompson AJ, Waubant E, Weinchenker BG and Wolinsky JS: Diagnostic Criteria for Multiple Sclerosis: 2010 Revision to the McDonald Criteria. Am Neurol 69: 292-302, 2011.

23. Lublin FD and Reingold SC: Defining the clinical course of multiple sclerosis: results of an international survey. National Multiple Sclerosis Society (USA) Advisory Committee on Clinical Trials of New Agents in Multiple Sclerosis. Neurology 46: 907-911, 1996

24. Kamali-Sarvestani E, Nikseresht A, Aflaki E, Sarvari J and Gharesi-Fard B: TNF- $\alpha$, TNF- $\beta$ and IL-4 gene polymorphisms in Iranian patients with multiple sclerosis. Acta Neurol Scand 115: 161-166, 2007.

25. Wu J-S, James I, Qiu W, Castley A, Christiansen FT, Carroll WM, Mastaglia FL and Kermode AG: HLA-DRB1 allele heterogeneity influences multiple sclerosis severity as well as risk in Western Australia. J Neuroimmunol 219: 109-113, 2010.

26. Comini-Frota ER, Rodrigues DH, Miranda EC, Drum DG, Kaimen-Maciel DR, Donadi EA and Teixeira AL: Serum levels of brain-derived neurotrophic factor correlate with the number of T2 MRI lesions in multiple sclerosis. Braz J Med Biol Res 45: 68-71, 2012.

27. Ministry of Health National Health Surveillance Agency Board (ANVISA): Resolution RDC no. 153, June 14, 2004. Official Gazette: 24 Jun, 2004, Brazil (In Portuguese).
28. Teunissem CE, Petzold A, Bennetm JL, Berven FS, Brudin L, Comabella M, Franciotta D, Frederiksen JL, Fleming JO, Furlan R, Hintzen RQ, Hughes SG, Johson MH, Krasulova E, Kuhle J, Magnone MC, Rjda C, Schimidt HK, Van Pesch V, Waubant E, Wolf C, Giovannoni G, Hemmer B, Tumani H and Deisenhammer F: A consensus protocol of the standardization of cerebral fluid collection and biobanking. Neurology 73: 1914-1922, 2009

29. Bielekova B and Martin R: Development of biomarkers in multiple sclerosis. Brain 127: 1463-1478, 2004

30. Giovannoni G, Green AJ and Thompson EJ: Are there any body fluid markers of brain atrophy in multiple sclerosis? Mult Scler 4: 138-142, 1998

31. Luomala M, Lehtimäki T, Huhtala H, Ukkonen M, Koivula T, Hurme $\mathrm{H}$ and Elovaara I: Promoter polymorphism of IL-10 and severity of multiple sclerosis. Acta Neurol Scand 108: 396-400, 2003.

32. Pulkkinen K, Luomala M, Kuusisto H, Lehtimäki T, Saarela M, Jalonen TO and Elovaara I: Increased in CCR5 Delta32/Delta32 genotype in multiple sclerosis. Acta Neurol Scand 109: 342-347, 2004.

33. Bahreini SA, Jabalameli MR, Saadatnia M and Zahednasab H: The role of non-HLA single nucleotide polymorphisms in multiple sclerosis susceptibility. J Neuroimmunol 229: 5-15, 2010.

34. Voskuhl RR and Gold SM: Sex-related factors in multiple sclerosis susceptibility and progression. Nat Rev Neurol 8: 255-263, 2012.

35. Ebers GC: PRISMS (Prevention of Relapses and Disability by Interferon $\beta-1$ a Subcutaneously in Multiple Sclerosis) Study Group. Randomized double blind placebo controlled study interferon beta 1a in relapsing/remitting multiples sclerosis. Lancet 352: 1498-1504, 1998.

36. Goodin DS, Frohman EM, Garmany GP Jr, Halper J, Likosky WH, Lublin FD, Silberberg DH, Stuart WH and van den Noort S: Disease modifying therapies in multiple sclerosis: reports of the therapeutics and technology assessment subcommittee of American Academy of Neurology and the MS Council for Clinical Practice Guidelines. Neurology 22: 169-178, 2002.

37. Raivich G and Banati R: Brain microglia and blood-derived macrophages: molecular profiles and functional roles in multiple sclerosis and animal models of autoimmune demyelinating disease. Brain Res Rev 46: 161-181, 2004

38. Chen YC, Yang X, Miao L, Liu ZG, Li W, Zhao ZX, Sun XL, Jiang GX, Chen SD and Cheng Q: Serum level of interleukin-6 in Chinese patients with multiple sclerosis. J Neuroimmunol 15: 109-111, 2012.

39. Nguyen LT, Ramanathan M, Weinstock-Guttman B, Baier M, Brownscheidle C and Jacobs LD: Sex differences in in vitro pro-inflammatory cytokine production from peripheral blood of multiple sclerosis patients. J Neurol Sci 209: 93-99, 2003.

40. Ramgolam VS, Sha Y, Jin J, Zhang X and Markovic-Plese S: IFN-beta inhibits human Th17 cell differentiation. J Immunol 183: 5418-5427, 2009.

41. John GR, Lee SC, Song X, Rivieccio M and Brosnan CF: IL-1-regulated responses in astrocytes: relevance to injury and recovery. Glia 49: 161-176, 2005.

42. Carlson NG, Wieggel WA, Chen J, Bacchi A, Rogers SW and Gahring LC: Inflammatory cytokines IL-1 alpha, IL-1 beta, IL-6 and TNF-alpha impart neuroprotection to an excitotoxin through distinct pathways. J Immunol 163: 3963-3968, 1999.

43. Navikas V, Matusevicius D, Söderström M, Fredrikson S, Kivisäkk P, Ljungdahl A, Höjeberg B and Link H: Increased interleukin- 6 mRNA expression in blood and cerebrospinal fluid mononuclear cells in multiple sclerosis. J Neuroimmunol 64: 63-69, 1996.

44. Imamura K, Suzumura A, Hayashi F and Marunouchi T: Cytokine production by peripheral blood monocytes/macrophages in multiple sclerosis patients. Acta Neurol Scand 87: 281-285, 1993.

45. Eugster HP, Frei K, Kopf M, Lassmann H and Fontana A: IL-6-deficient-mice resist myelin oligodendrocyte glycoprotein-induced autoimmune encephalomyelitis. Eur J Immunol 28: 2178-2187, 1998

46. Schindler R, Mancilla J, Endres S, Ghorbani R, Clark SC and Dinarello CA: Correlations and interactions in the production of interleukin-6 (IL-6), IL-1 and tumor necrosis factor (TNF) in human blood mononuclear cells: IL-6 suppresses IL-1 and TNF. Blood 75: 40-47, 1990.

47. Tilg H, Trehu E, Atkins MB, Dinarello CA and Mier JW: Interleukin-6 (IL-6) as an anti-inflammatory cytokine: induction of circulating IL-1 receptor antagonist and soluble tumor necrosis factor receptor p55. Blood 83: 113-118, 1994. 
48. Navikas V, Link J, Palasik W, Söderstrom M, Fredrikson S, Olsson T and Link H: Increased mRNA expression of IL-10 in mononuclear cells in multiple sclerosis and optic neuritis. Scand J Immunol 41: 171-178, 1995.

49. Hirano T: Interleukin-6. In: The Handbook of Cytokines. Thompson (ed.) Academic Press, London, pp145-169, 1994.

50. Cooke A: Th17 cells in inflammatory conditions. Rev Diabet Stud 3: 72-75, 2006

51. Brucklacher-Waldert V, Stuerner K, Kolster M, Wolthausen J and Tolosa E: Phenotypical and functional characterization of T helper 17 cells in multiple sclerosis. Brain 132: 3329-3341, 2009.

52. Langrish CL, Chen Y, Blumenschein WM, Mattson J, Basham B, Sedgwick JD, Mcclanahan T, Kastelein RA and Cua DJ: IL-23 drives a pathogenesis $\mathrm{T}$ cell population that induces autoimmune inflammation. J Exp Med 20: 233-240, 2005.

53. Harrington LE, Mangan PR and Weaver CT: Expanding the effector CD4 T-cell repertoire: the Th17 lineage. Curr Opn Immunol 18: 349-356, 2006.

54. Van Wagoner NJ and Benveniste EN: Interleukin-6 expression and regulation in astrocytes. J Neuroimmunol 100: 124-139, 1999.

55. Windhagen A, Newcombe J, Dangond F, Strand C, Woodroof MN, Cuzner ML and Hafler DA: Expression of costimulatory molecules B7-1 (CD28), B7-2 (CD86) and interleukin 12 cytokine in multiple sclerosis lesions. J Exp Med 182: 1985-1996, 1995.

56. Campbell IL, Stalder AK, Akwa Y, Pagenstecher A and Asensio VC: Transgenic models to study the actions of cytokines in the central nervous system. Neuroimmunomodulation 5: 126-135, 1998

57. Byrnes AA, Mcarthur JC and Karp CL: Interferon-beta therapy for multiple sclerosis induces reciprocal changes in interleukin-12 and interleukin-10 production. Ann Neurol 51: $165-174,2002$

58. Wang X, Chen M, Wandinger KP, Willians G and Dhib-Jalbut S: IFN-beta-1b inhibits IL-12 production in peripheral blood mononuclear cells in an IL-10-dependent mechanism: relevance to IFN-beta-1b therapeutic effects in multiple sclerosis. J Immunol 165: 548-557, 2000

59. Kuchroo VK, Das MP, Brown JA, Ranger AM, Zamvil SS, Sobel RA, Weiner HL, Nabavi N and Glimcher LH: B7-1 and B7-2 costimulatory molecules activate differentially the Th1/ Th2 developmental pathways: application to autoimmune disease therapy. Cell 80: 707-718, 1995.

60. Mikulkova Z, Praksova P, Stourac P, Bednarik J and Michalek J: Imbalance in T-cell and cytokine profiles in patients with relapsing-remitting multiple sclerosis. J Neurol Sci 300: 135-141, 2011.

61. Begolka WS and Miller SD: Cytokines as intrinsic and exogenous regulators of pathogenesis in experimental autoimmune encephalomyelitis. Res Immunol 149: 771-781, 1998.

62. Cannella B and Raine CS: The adhesion molecule and cytokine profile of multiple sclerosis lesions. Annals Neurol 37: 424-435, 1995.

63. Samoilova EB, Horton JL and Chen Y: Acceleration of experimental autoimmune encephalomyelitis in interleukin-10-deficient mice: roles of interleukin-10 in disease progression and recovery. Cell Immunol 188: 118-124, 1998.
64. Marques M: Multiple sclerosis - Forms and phases of the disease. In: Multiple Sclerosis Introduction. Pedrosa R (ed). Elaborated by the Neurology Portuguese Society. 1st edition. Biogen Indec Portugal, Lisboa, pp155-161, 2010.

65. Brandão CO, Ruocco HH, Farias Ados S, Oliveira C, Hallal-Longo DE, Mirandola SR, Oliveira EC, Cendes F, Damasceno BP and Santos LM: Cytokines and intrathecal IgG synthesis in multiple sclerosis patients during clinical remission. Arq Neuro Psiquiatr 63: 914-919, 2005.

66. Beck J, Rondot P, Catinot L, Falcoff E, Kirchner H and Wietzerbin J: Increased production of interferon gamma and tumor necrosis factor precedes clinical manifestations in multiple sclerosis: do cytokines trigger off exacerbations? Acta Neurol Scand 78: 318-323, 1998.

67. Becher B, Giacomini PS, Pelletier D, Mccrea E, Prat A and Antel JP: Interferon-gamma secretion by peripheral blood T-cell subsets in multiple sclerosis: correlation with disease phase and interferon-beta therapy. Ann Neurol 45: 247-250, 1999.

68. Pouly S, Becher B, Blain M and Antel JP: Interferon-gamma modulates human oligodendrocyte susceptibility to Fas-mediated apoptosis. J Neuropathol Exp Neurol 59: 280-286, 2000.

69. Ehling R, Gassner Ch, Lutterotti A, Strasser-Fuchs S, Kollegger H, Kristoferitsh W, Reindl M and Berger T: Genetic variants in the tumor necrosis factor receptor II gene in patients with multiple sclerosis. Tissue Antigens 63: 28-33, 2004.

70. Benvenuto R, Paroli M, Buttinelli C, Franco A, Barnaba V, Fieschi $\mathrm{C}$ and Balsano F: Tumor necrosis factor-alpha synthesis by cerebrospinal-fluid-derived $\mathrm{T}$ cell clones from patients with multiple sclerosis. Clin Exp Immunol 84: 97-102, 1991.

71. Selmaj K, Raine CS, Cannella B and Brosnan CF: Identification of lymphotoxin and tumor necrosis factor in multiple sclerosis lesions. J Clin Invest 87: 949-954, 1991.

72. Schönrock LM, Gawlowski G and Brück W: Interleukin-6 expression in human multiple sclerosis lesions. Neurosci Lett 294: 45-48, 2000.

73. van Boxel-Dezaire AH, Hoff SC, Van Oosten BW, Verweij CL, Dräger AM, Adèr HJ, Van Houwelingen JC, Barkhof F, Polman $\mathrm{CH}$ and Nagelkerkern L: Decreased interleukin-10 and increased interleukin-12p40 mRNA are associated with disease activity and characterize different disease stages in multiple sclerosis. Ann Neurol 45: 695-703, 1999.

74. Iwakura $\mathrm{Y}$ and Ishigame H: The IL-23/IL-17 axis in inflammation. J Clin Invest 116: 1218-1222, 2006.

75. Lock C, Hermans G, Pedotti R, Brendolan A, Schadt E, Garren H, Langer-Gould A, Strober S, Cannella B, Allard J, Klonowski P, Austin A, Lad N, Kaminski N, Galli SJ, Oksenberg JR, Raine CS, Heller R and Steinman L: Gene-microarray analysis of multiple sclerosis lesions yields new targets validated in autoimmune encephalomyelitis. Nat Med 8: 500-508, 2002.

76. Pelfrey CM, Rudick RA, Cotleur AC, Lee JC, Tary-Lehmann M and Lehmann PV: Quantification of self-recognition in multiple sclerosis by single cell analysis of cytokine production. J Immunol 165: 1641-1651, 2000. 